\title{
Development of Learning and Memory in Aplysia. II. Habituation and Dishabituation
}

\author{
Catharine H. Rankin and Thomas J. Carew \\ Departments of Psychology and Biology, Yale University, New Haven, Connecticut 06520
}

The defensive withdrawal reflex of the mantle organs of Aplysia californica exhibits a variety of forms of both nonassociative and associative learning, which can exist in both short- and long-term forms. In addition, the reflex can be readily elicited and quantified as soon as the effector organs (siphon and gill) emerge at their respective developmental stages. Thus, this reflex system provides a useful preparation in which to study the development of learning and memory.

In the present series of experiments we investigated the development of 2 forms of nonassociative learning, habituation and dishabituation, in the siphon withdrawal component of the reflex. This reflex response could be examined throughout the juvenile life of the animal (stages 9-12) since the reflex is functionally intact as soon as the siphon emerges in stage 9 (Rankin et al., 1987). We studied the development of habituation in stages 9-12 using tactile stimuli to the siphon delivered at interstimulus intervals (ISIs) of $1,5,10$, and 30 sec. Habituation of siphon withdrawal was evident as early as juvenile stage 9 . However, it existed in an immature form: Significant habituation was produced only with a very short $(1 \mathrm{sec})$ ISI. No significant habituation occurred in response to 5 or 10 sec ISIs. Approximately 4 d later, in stage 10, significant habituation occurred to both 1 and 5 sec ISIs but not to a $10 \mathrm{sec}$ ISI. Finally, approximately 1-2 weeks later, in stage 11, significant habituation occurred to 1,5 , and 10 sec ISIs but not to a $30 \mathrm{sec}$ ISI, whereas stage 12 juveniles and adults (stage 13) readily habituated to a $30 \mathrm{sec}$ ISI. Thus, there was a systematic developmental trend in the ability of the animals to habituate: Progressively older animals were capable of habituation to stimuli presented at progressively longer intervals.

The systematic development of habituation was also evident by examining the amount of habituation exhibited to comparable ISIs by animals at different developmental stages. For all 4 ISIs examined, older animals showed significantly greater habituation than younger animals. Thus, our results show that habituation is present as soon as the siphon response system emerges and that it develops pro-

Received Apr. 1, 1986; revised June 30, 1986; accepted July 1, 1986.

We wish to thank Steven Brake, Michael Davis, Emilie Marcus, Thomas Nolen, and Allan Wagner for helpful criticism of an earlier version of this manuscript and Eisha Lee for her artwork in Figure 1. We also thank the Howard Hughes Medical Institute and Tom Capo for generously supplying juvenile Aplysia. This work was supported by NIH CDA Award 7-K02-MH00081-09, NIH BRSG Grant 507-RR-0750 15, and NSF Grant BNS 831130 (T.J.C.).

Correspondence should be addressed to Thomas J. Carew, Department of Psychology, Yale University, P.O. Box 11A, Yale Station, New Haven, CT 06520.

Copyright (C) 1987 Society for Neuroscience $0270-6474 / 87 / 010133-11 \$ 02.00 / 0$ gressively throughout the juvenile life of the animal.

Whereas habituation was present in the earliest developmental stage we examined (stage 9), dishabituation (in response to tail shock) did not emerge until 4-7 d later, in stage 10. Thus, it appears that the simplest form of nonassociative learning, habituation, developmentally precedes a somewhat more complex form, dishabituation, raising the possibility that even more complex forms of learning in this reflex, such as classical conditioning, may emerge even later in development.

A fundamental question in the analysis of the neural control of behavior concerns the mechanisms underlying learning and memory. A number of divcrse bchavioral, neurophysiological, and neuropharmacological approaches have been brought to bear on this issue, which have greatly increased our understanding of possible neuronal substrates of learning and memory (for recent reviews, see Lynch et al., 1984; Squire and Butters, 1984; Carew and Sahley, 1986; Hawkins et al., 1986). One strategy that has recently proven to be valuable has been a developmental approach. This kind of analysis involves the investigation of the way in which different learning and memory processes emerge and are interrelated during ontogeny. The power of this approach is that it permits establishing relationships between the emergence of particular forms of learning and the emergence of specific neural structures or circuits, relationships that may be very difficult (or in some cases impossible) to establish in adult animals. In recent years, this kind of developmental approach has been applied to a variety of forms of learning, especially in altricial mammalian species, which are born with relatively immature nervous systems and thus are well suited for such an analysis (for reviews, see Campbell and Spear, 1972; Campbell and Coulter, 1976; Amsel and Stanton, 1980).

Another approach to the analysis of learning and memory that has proven quite valuable in recent years has been the use of invertebrate animals. Several invertebrate preparations have now bcen developed in which it is possible to specify the neuronal circuitry involved in learning, and in some cases it has been possible to analyze aspects of the biophysical and molecular mechanisms underlying learning (for reviews, see Quinn, 1984; Carew and Sahley, 1986; Hawkins et al., 1986). It is the conceptual framework of the present work to extend the power of an invertebrate approach to an analysis of the development of learning and memory in Aplysia californica.

The defensive withdrawal reflex of the mantle organs of Aplysia is well suited for a developmental analysis of learning for several reasons. First, both gill and siphon withdrawal can be readily elicited and quantified as soon as each organ emerges 

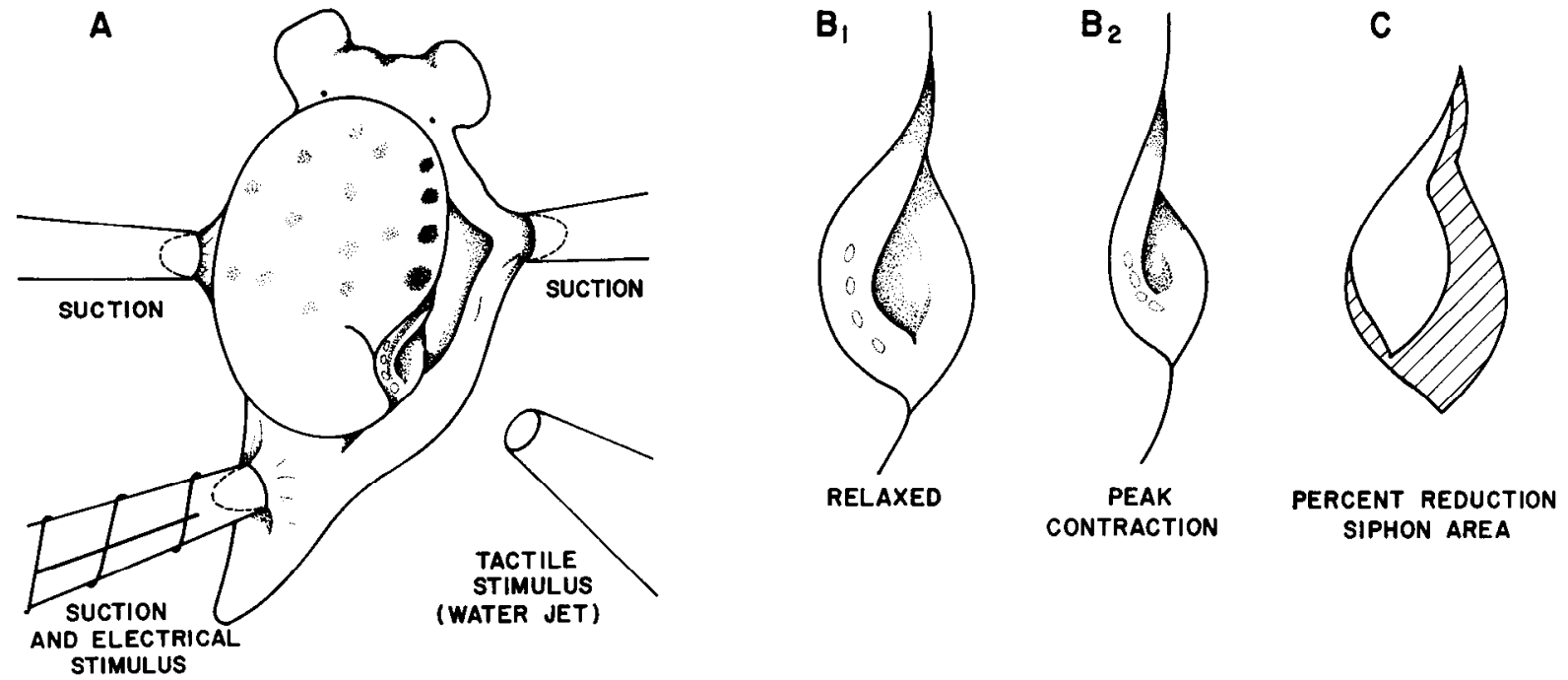

Figure 1. Experimental preparation for the study of habituation and dishabituation of the siphon withdrawal reflex. $A$, Stage 10 juvenile restrained with 3 suction pipettes. The reflex is evoked with a brief tactile stimulus (water jet) to the siphon. For dishabituation, a brief electric shock is delivered through the pipette on the tail. $B, C$, Quantification of the reflex contraction. $B_{1}$, Enlarged view of the relaxed siphon (130 $\mu \mathrm{m}$ in length along its long axis) $1 \mathrm{sec}$ prior to stimulation. $B_{2}$, Peak of the contraction following tactile stimulation. $C$, Superimposed outlines of $B_{1}$ and $B_{2}$. Reduction in siphon area (hatched portion) is used as a measure of response amplitude.

during development (Rankin et al., 1987). Second, in the adult this reflex exhibits a variety of forms of both nonassociative learning (such as habituation, dishabituation, and sensitization) and associative learning (such as differential classical conditioning and operant conditioning), many of which can exist in both short- and long-term forms (Pinsker et al., 1970, 1973; Carew et al., 1972, 1983; Hawkins et al., 1986). Third, the neural circuit of this reflex is well understood in the adult, and significant progress has been made in specifying the synaptic, biophysical, and molecular mechanisms underlying both nonassociative and associative learning in this reflex system (Klein and Kandel, 1978, 1980; Castellucci et al., 1980, 1982; Seigelbaum et al., 1982; Hawkins et al., 1983; Kandel et al., 1983; for review, see Carew, 1986; Hawkins et al., 1986). Finally, the development of the CNS, including the abdominal ganglion that mediates this reflex, has been examined in considerable detail (Kriegstein et al., 1974; Kriegstein, 1977a, b; Schacher et al., 1979a, b; Rayport and Kandel, 1980; Jacob, 1984). Thus, from behavioral, cellular, and developmental perspectives, the defensive withdrawal reflex of Aplysia is well suited for an analysis of the ontogeny of learning.

As a first step in this analysis, we have examined the ontogeny of 2 different forms of nonassociative learning, habituation and dishabituation. Dishabituation is often considered to reflect a special instance of a generalized facilitatory process, sensitization (Thompson and Spencer, 1966; Groves and Thompson, 1970; Carew et al., 1971). However, we have recently found that dishabituation and sensitization emerge at very different times during development in Aplysia (Rankin and Carew, 1986), suggesting the possibility, as Hochner and colleagues (1986) first pointed out, that they may, at least in part, be mediated by different mechanisms. In the present experiments we have restricted our studies to an examination of facilitation of habituated responses and thus will use the more restricted term, dishabituation, to describe this form of response enhancement (see Discussion). We have found that habituation emerges at a distinct and earlier stage in development than dishabituation.
We have also found that the capacity for short-term memory appears to develop gradually and systematically throughout the juvenile life of the animal.

Some of the results presented in this paper have been previously presented in preliminary form (Rankin and Carew, 1985).

\section{Materials and Methods}

Animals. Sixty juvenile $A$. californica ranging from 0.8 to $10.0 \mathrm{~mm}$ in length were used. The animals were laboratory-cultured specimens obtained from the Howard Hughes Medical Institute, Woods Hole, MA. The animals were maintained in groups of $4-8$ on seaweed (Gracillaria) in $50 \mathrm{ml}$ plastic centrifuge tubes filled with seawater $\left(15^{\circ} \mathrm{C}\right)$ obtained from Woods Hole, MA. Animals were maintained in our laboratory for at least $24 \mathrm{hr}$ prior to their use. We studied animals that were in developmental stages 9-12 as defined by Kriegstein (1977b) (see also Rankin et al., 1987). Briefly, stage 9 lasts about $4 \mathrm{~d}$ and the animals are $0.8-1 \mathrm{~mm}$ in length; stage 10 lasts about 7 days and the animals are $1.0-1.5 \mathrm{~mm}$ in length; stage 11 lasts about 30 days and the animals are about $2.0-4.0 \mathrm{~mm}$ in length; and stage 12 lasts about 60 days and the animals we used were about 6.0 to $10.0 \mathrm{~mm}$ in length. Adult Aplysia weighing 150-200 gm were obtained from Pacific Bio-Marine, Venice, CA.

Behavioral procedures. The animals were restrained in a petri dish containing freshly aerated Woods Hole seawater by applying gentle negative pressure to their sides and tail through 3 suction electrodes pulled from plastic tubing (Fig. $1 A$ ). To study habituation, brief (50 $\mathrm{msec}$ ) water jet stimuli were delivered to the siphon through a micropipette connected to a Picospritzer II (a constant-pressure injection device, General Valve Corp.). To study dishabituation, brief electrical shocks were delivered through the third suction electrode to the animal's tail. Responses were recorded on videotape for later analysis.

Since animals of different sizes were used in the study, it was important to develop a normalization procedure to permit comparable stimulus delivery to all animals. The micropipette from the Picospritzer was first aimed at the siphon by bringing it up to touch the siphon. It was then gradually moved away in a direction parallel to the long axis of the pipette, until the tip was a considerable distance from the siphon, just below the water surface. A threshold stimulus for a siphon withdrawal response was obtained by triggering a constant-intensity microjet of seawater aimed at the siphon at progressively closer distances, in about $1 \mathrm{~mm}$ increments, until a withdrawal response was seen. The water jet micropipette was then advanced an additional $30 \%$ of the total distance to the siphon. This stimulus intensity (approximately $4 \mathrm{mg}$ ) produced 


\section{SECOND ISI}
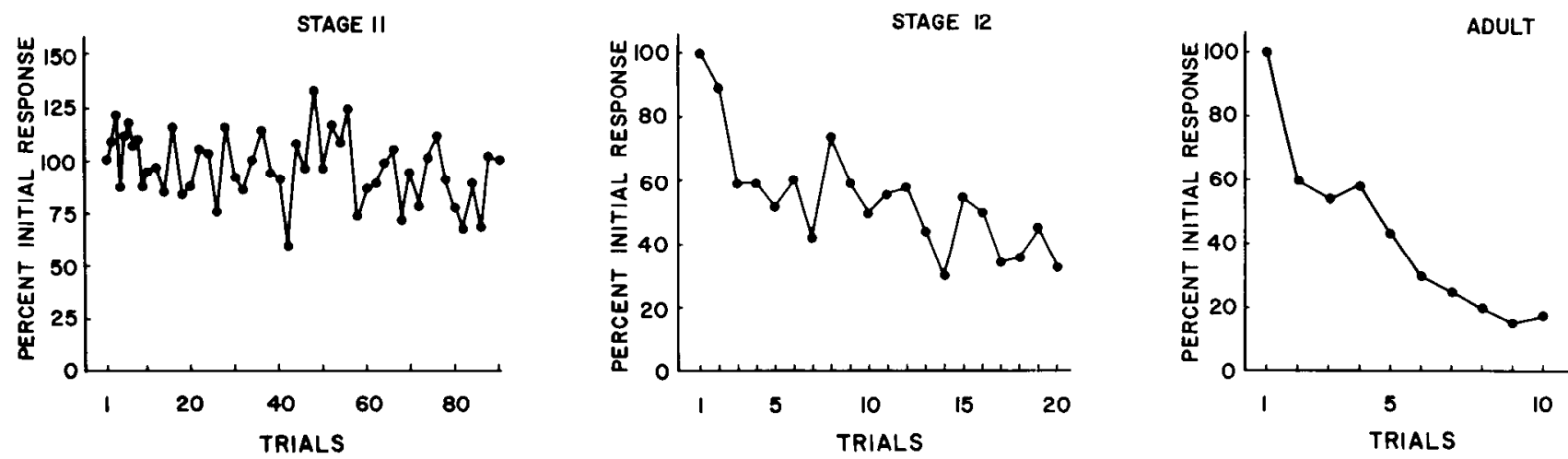

Figure 2. Habituation in late juvenile stages. Habituation of siphon withdrawal to stimuli delivered at a 30 sec ISI is shown in late juvenile animals: stage $11(n=5)$, stage $12(n=5)$, and adult $(n=4)$. Data are expressed as the mean percentage of initial response. There was no significant habituation in stage 11 animals, whereas both stage 12 and adult animals showed significant habituation; however, there was significantly greater habituation in adults than in stage 12 animals.

a responsc that was about $50 \%$ of maximum (see Rankin et al., 1987, for details). The animal was rested for $15 \mathrm{~min}$ before habituation trials began. Four interstimulus intervals (ISIs) were used: $30,10,5$, and 1 sec. Independent groups ( $n=5$ per group) were used for each ISI examined in each developmental stage. For the 30, 10, and $5 \mathrm{sec}$ ISIs, 90 water jet stimuli were delivered and the siphon withdrawal response was recorded for each. The 90 stimuli were followed by a dishabituating stimulus consisting of 2 trains of electrical pulses to the tail, which produced dramatic siphon withdrawal in animals of all stages. Each train consisted of $5 \mathrm{msec} 110 \mathrm{~V}$ pulses delivered at a frequency of $7 \mathrm{~Hz}$ for $700 \mathrm{msec}$. When the siphon had relaxed after the dishabituating stimulus, an additional 15 water jet stimuli were delivered at the original ISI. Experiments using the $1 \mathrm{sec}$ ISI required a modified procedure since the siphon withdrawal response often lasted longer than $1 \mathrm{sec}$. An initial test with a single water jet was delivered, followed within 5 sec by the $1 \mathrm{sec}$ ISI habituation procedure. This procedure consisted of $10 \mathrm{blocks}$ of stimulation. Each block consisted of 10 water jet stimuli (with a 1 sec ISI) followed by a single test water jet stimulus to assess habituation as soon as the siphon relaxed (within $5-10 \mathrm{sec}$ ). The dishabituating stimulus was delivered as described above, followed by a single water jet test pulse and then by 4 blocks of 10 stimuli (as above), with each block followed by a test pulse.

Scoring. Behavioral responses were scored using a modification of the procedure used by Carew et al. (1979). A piece of clear acetate was placed over the video monitor screen, and, using slow-motion and stopframe playback, the perimeter of the siphon was traced immediately prior $(1 \mathrm{sec})$ to a stimulus and again when the siphon contraction was at its maximum (with repeated slow-motion playback, maximum contraction could be objectively determined). For the 5, 10, and $30 \mathrm{sec}$ ISI trials, the first 10 responses were scored and then every second response up to 90 was scored; the 15 postsensitization responses were each scored. For the $1 \mathrm{sec}$ ISI trials, the response to each test pulse was scored.

The tracings were then digitized using a bit pad (Bioquant HIPAD) and a microcomputer (IBM PC-XT) in conjunction with software (Bioquant) that provided a quantitative measure of the net area of the siphon before and after the water jet stimulus. The response amplitude was then quantified by computing a percentage difference score between the area of the contracted siphon and the area of the relaxed siphon (Fig. $1 B$ ), and the data were normalized by expressing all responses as percentages of the initial response in a habituation run, which were then plotted against stimulus number. Response magnitude was measured in terms of response amplitude, since response duration in juveniles provides a morc variablc cstimate of reflex magnitude. This is in contrast to adult Aplysia, in which reflex amplitude and duration are highly correlated (M. Stopfer and T. J. Carew, unpublished observations).

In adult animals, siphon withdrawal was elicited by means of a nylon bristle (Carew et al., 1981) in a restrained preparation (Pinsker et al., 1970; Carew et al., 1979; see also Rankin et al., 1987). The nylon bristle produces both qualitatively and quantitatively similar response decre- ment during habituation as does a water jet stimulus, e.g., from a Water Pik (Pinsker et al., 1970; Carew et al., 1972). The response was quantified in terms of its duration, measured from stimulus onset until the siphon returned to $75 \%$ of its original (resting) length.

Statistical analysis. Between-group comparisons were made using $t$ tests for independent means. The magnitude of habituation was determined by a percentage habituation score, which expressed the percentage reduction of the averaged last 3 responses compared with the initial response. Thus, complete habituation (averaged last 3 responses $=0$ ) would yield a habituation score of $100 \%$. For experiments using a $1 \mathrm{sec}$ ISI, only the last (test) response was compared with the initial response (see below). If more than 2 groups were used in an experiment, a 1 -way ANOVA was used to determine overall significance, followed by Newman-Keuls planned comparisons (Winer, 1962).

Within-group comparisons were made by means of $t$ tests for correlated means. Such comparisons were used to assess the significance of both habituation and dishabituation. To assess habituation, each animal contributed a single score, which was the normalized difference between its first score and the averaged last 3 scores for the habituation run. To assess dishabituation, each animal contributed a single score, which was the difference between the averaged last 3 scores of each habituation run and the averaged first 3 scores following tail shock. For the $1 \mathrm{sec}$ ISI, in which habituation and dishabituation were assessed by single test stimuli intercalated between blocks of 10 stimuli, habituation difference scores were computed for the first and last scores for each habituation run, and dishabituation difference scores were computed from the last score in the habituation run and the first score following tail shock.

In 1 experiment (stage 11 animals, $1 \mathrm{sec}$ ISI), all 5 animals yielded a normalized initial score of $100 \%$ and a habituation score of $0.0 \%$; thus, a parametric analysis on these data was inapplicable (since the variance for pre- and postscores was 0.0 ). In this case, the raw (nonnormalized) scores for each animal were used for the within-group analysis. The mean initial score $(n=5)$ was $41.95 \pm 4.09 \%$; the mean final score was $0.0 \mathrm{sec}\left(t_{4}=10.26, p<0.001\right)$

All probability values are 2-tailed. Data are expressed in means, and where between-group comparisons are made, variance is shown as SEM.

\section{Results}

The preparation we used to examine habituation and dishabituation in young juvenile animals is illustrated in Figure 1, which shows a stage 10 animal restrained by the 3 suction micropipettes (Fig. 1A). For the habituation trials a brief water jet stimulus was delivered to the siphon. Dishabituating stimuli were delivered through a suction electrode attached to the tail. Siphon contractions were quantified from the videotapes as illustrated 
in Figure $1 B$ (for details, see Materials and Methods)

Every animal at each stage tested (stages 9-12) responded to the water jet stimulus to the siphon with a brisk withdrawal reflex of the siphon. Moreover, animals at each stage responded to the electrical stimulus to the tail by contracting all parts of their body, including the siphon. Approximately $30 \%$ of the animals in each stage exhibited a defensive inking response (Carew and Kandel, 1977) to the tail shock used to produce dishabituation.

In addition to the responses elicited by the water jet stimuli, spontaneous contractions of the siphon occurred in all animals throughout each series of trials (see Rankin et al., 1987). A spontaneous contraction caused the siphon, the mantle, and the edges of the parapodia to contract maximally and remain contracted for 2-5 sec. Responses to water jet stimuli that coincided with spontaneous contractions were not scored.

\section{Habituation in late juvenile stages}

We began our study of the development of habituation by examining animals in the relatively late juvenile stages 11 and 12 . In adult Aplysia, a $30 \mathrm{sec}$ ISI is known to produce profound response decrement (Carew et al., 1972). We therefore first used a $30 \mathrm{sec}$ ISI to examine whether older juvenile animals could habituate to stimuli presented at this interval. Three groups of animals were examined: adults, stage 12 , and stage 11 . The results are shown in Figure 2. An ANOVA revealed an overall significant difference in the amount of habituation exhibited by animals at different developmental stages $(\mathrm{F}(2,11)=3.5, p<$ $0.05)$. Subsequent within-group comparisons showed that adults $(n=4)$ and stage 12 animals $(n=5)$ exhibited significant habituation $\left(t_{3}=18.29, p<0.001\right.$ and $t_{4}=12.6, p<0.001$, respectively; Fig. 2), whereas stage 11 animals $(n=5)$ showed no significant habituation at this ISI $\left(t_{4}=0.32, p>0.50\right)$ even after 90 trials. Moreover, a clear developmental trend was evident since there was significantly greater habituation in adults than in stage 12 animals $\left(t_{7}=3.27, p<0.02\right)$. We also observed greater variability in the responses of younger animals (Fig. 2), which appeared to diminish with progressively later developmental stages.

In summary, although the $30 \mathrm{sec}$ ISI was highly effective in producing habituation in adults and late juveniles (stage 12), it was ineffective in stage 11 animals. We therefore chose to use shorter ISIs, specifically 10,5 , and $1 \mathrm{sec}$, to probe the development of habituation in younger juvenile animals.

\section{Stage 11 animals}

\section{Habituation}

The results for stage 11 animals are shown in Figure 3. Animals at this stage exhibited significant habituation in response to stimuli at all three ISIs used ( 10,5 , and $1 \mathrm{sec} ; n=5$ per stage). Thus, the averaged last 3 responses of the run for each interval were significantly lower in amplitude than the first response: 10 $\sec$ ISI $\left(t_{4}=7.8, p<0.01\right) ; 5 \mathrm{sec}$ ISI $\left(t_{4}=11.7, p<0.001\right)$; and $1 \mathrm{sec}$ ISI $\left(t_{4}=10.26, p<0.001\right)$. An ANOVA revealed an overall significant difference in the magnitude of habituation produced by different ISIs $(\mathrm{F}(2,12)=9.73, p<0.0002)$. Moreover, a clear trend emerged in the percentage habituation as a function of ISI: 10 sec ISI, $\bar{X}=66 \pm 8.5 \% ; 5$ sec ISI, $\bar{X}=70 \pm 5.9 \% ; 1$ sec ISI, $\bar{X}=100 \pm 0 \%$. However, ascribing this trend solely to the differences in ISI training is complicated by the fact that animals were tested using different intervals (see Discussion).
In summary, at 10,5 , and $1 \mathrm{sec}$ ISIs, stage 11 juveniles exhibit significant habituation (Fig. 3). However, habituation has not yet reached its mature form in stage 11 , since animals at this stage do not habituate at longer ISIs $(30 \mathrm{sec})$, whereas stage 12 and adult animals readily habituate at a $30 \mathrm{sec}$ ISI (Fig. 2).

\section{Dishabituation}

For each ISI used, tail shock produced dishabituation, as was evident by the marked increase in response amplitude following the delivery of the shock (indicated by arrows in Fig. 3). Thus, siphon response amplitude in the first 3 responses following tail shock was significantly increased compared with that in the last 3 responses prior to shock ( $10 \mathrm{sec}$ ISI, $t_{4}=5.34, p<0.01 ; 5$ sec ISI, $t_{4}=3.8, p<0.02 ; 1 \mathrm{sec}$ ISI, $t_{4}=8.64, p<0.001$ ).

\section{Stage 10 animals}

\section{Habituation}

The results for stage 10 animals are shown in Figure 4 . In contrast to stage 11 animals, stage 10 animals $(n=5)$ did not exhibit significant habituation $\left(t_{4}=1.4, p>0.25\right)$ to stimuli delivered at a $10 \mathrm{sec}$ ISI. However, significant habituation was evident for the 5 and $1 \mathrm{sec}$ ISIs $\left(t_{4}=10.3, p<0.001\right.$, and $t_{4}=20.8$, $p<0.001$, respectively). As in the stage 11 animals, significantly greater habituation was produced by shorter ISIs. An ANOVA revealed an overall significant difference in the percentage habituation as a function of ISI $(F(2,12)=3.89, p<0.025)$. In addition, once again a clear trend in the percentage habituation was observed: $10 \mathrm{sec}$ ISI, $\bar{X}=32.6 \pm 23.2 \%$; 5 sec ISI, $\bar{X}=$ $72.6 \pm 7.06 \%$; $1 \mathrm{sec}$ ISI, $\bar{X}=88.6 \pm 7.3 \%$.

\section{Dishabituation}

For both the 5 and $1 \mathrm{sec}$ ISIs, tail shock produced significant dishabituation (Fig. 4). In each case the first 3 responses following the shock were significantly greater in amplitude than the last 3 habituated responses prior to shock $\left(t_{4}=3.01, p<0.05\right.$; and $t_{4}=3.9, p<0.02$, respectively). Interestingly, tail shock did not produce facilitation of the nonhabituated responses evident at the $10 \mathrm{sec}$ ISI (Fig. 4). This could be the result of a ceiling effect. That is, the responses may already be close to their maximum amplitude and thus may not be able to be augmented further. However, the stimulus intensity used in these experiments produced responses that were typically $50 \%$ of maximum (see Materials and Methods), and responses greater in magnitude than the initial response (i.e., $>100 \%$ ) were observed in all stages examined (Figs. 3-5), making a ceiling effect less likely. Another possibility, however, is that the capacity for sensitization may not yet have emerged in this stage of development, even though the capacity for dishabituation is present (see Discussion).

\section{Stage 9 animals}

\section{Habituation}

The results for stage 9 animals are shown in Figure 5. Habituation in stage 9 animals appeared to be less well developed than in older juvenile stages. Specifically, no significant habituation was observed with either $10 \sec \left(t_{4}=0.93\right)$ or $5 \sec \left(t_{4}=\right.$ 0.74 ) ISIs ( $p>0.50$ in each case; Fig. 5; however, see below). Only a $1 \mathrm{sec}$ ISI produced significant habituation $\left(t_{4}=5.12, p<\right.$ $0.01)$. As in the other stages, there was a significant effect of ISI on the magnitude of habituation $(\mathrm{F}(2,12)=3.99, p<0.025)$. This is attributable to the fact that significant habituation was seen only at a $1 \mathrm{sec}$ ISI: $10 \mathrm{sec}$ ISI, $\bar{X}=6.6 \pm 8.9 \% ; 5 \mathrm{sec}$ ISI, 
STAGE II
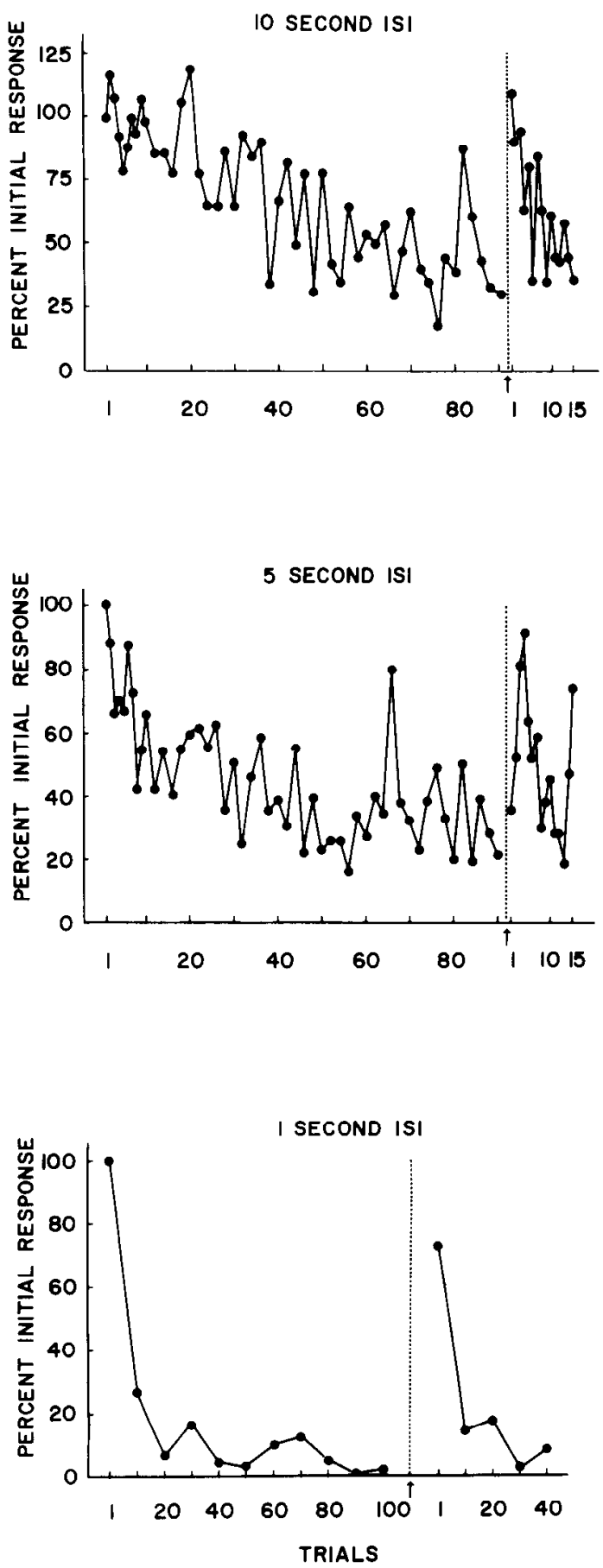

Figure 3. Habituation and dishabituation in stage 11 animals. ISIs of 10,5 , and $1 \sec (n=5$ for each) were used. The curve at left for each ISI shows the relative response amplitude for habituation trials. The dashed line and arrow indicate the delivery of tail shock. The curve at right of the dashed line represents the post-tail shock trials. There was significant habituation and dishabituation for each of the 3 ISIs.

$\bar{X}=10.1 \pm 10.8 \% ; 1 \mathrm{sec}$ ISI, $\bar{X}=47.8 \pm 13.9 \%$.

Although significant habituation occurred at a $1 \mathrm{sec}$ ISI, the acquisition profile appeared to be modest when compared with comparable ISIs at older developmental stages (compare $1 \mathrm{sec}$ ISIs in Figs. 3-5). However, we found that the magnitude of
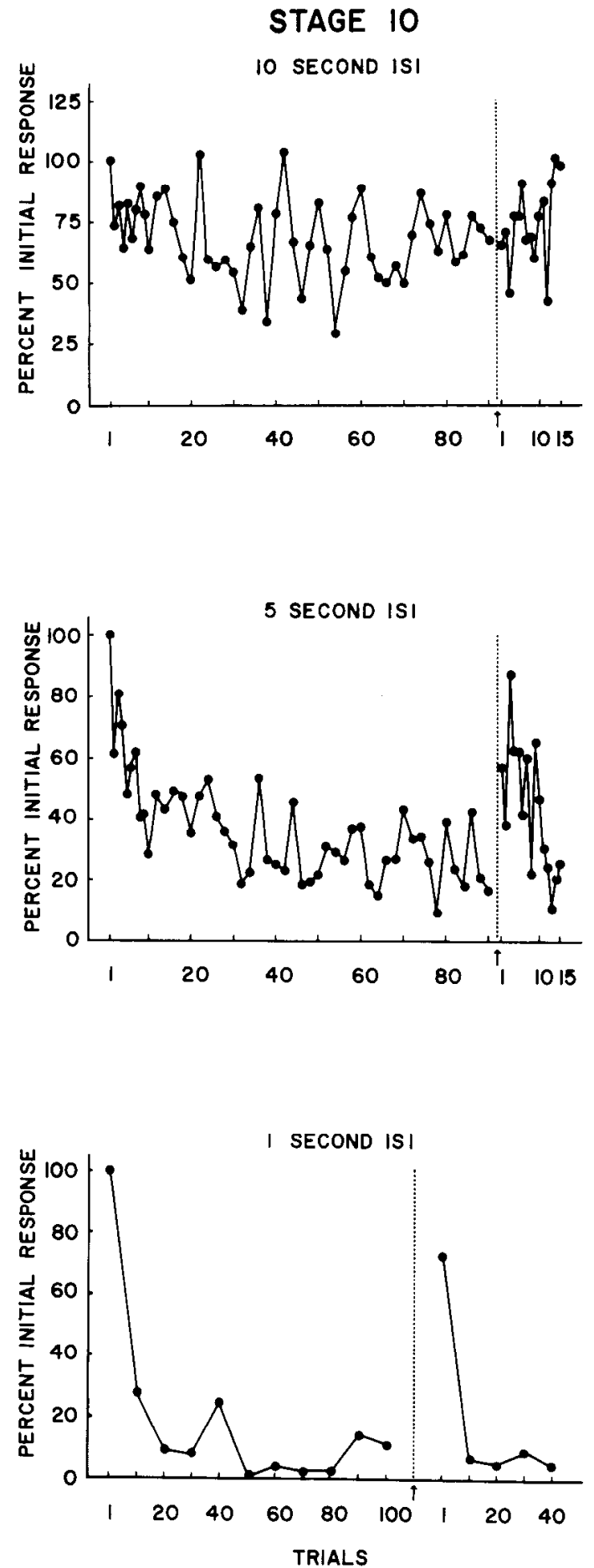

Figure 4. Habituation and dishabituation in stage 10 animals. ISIs of 10,5 , and $1 \sec (n=5$ for each) were used. The dashed line and arrow represent tail shock. There was significant habituation and dishabituation to both the 5 and $1 \mathrm{sec}$ ISI but not to the $10 \mathrm{sec}$ ISI.

response decrement produced by training with a $1 \mathrm{sec}$ ISI in a stage 9 animal could be significantly enhanced if that training were preceded by training with a $10 \mathrm{sec}$ ISI, even though the $10 \mathrm{sec}$ ISI itself produced no habituation (Fig. 6). After animals received habituation and dishabituation training at a $10 \mathrm{sec}$ ISI, they were rested $15 \mathrm{~min}$ and then received an additional 90 

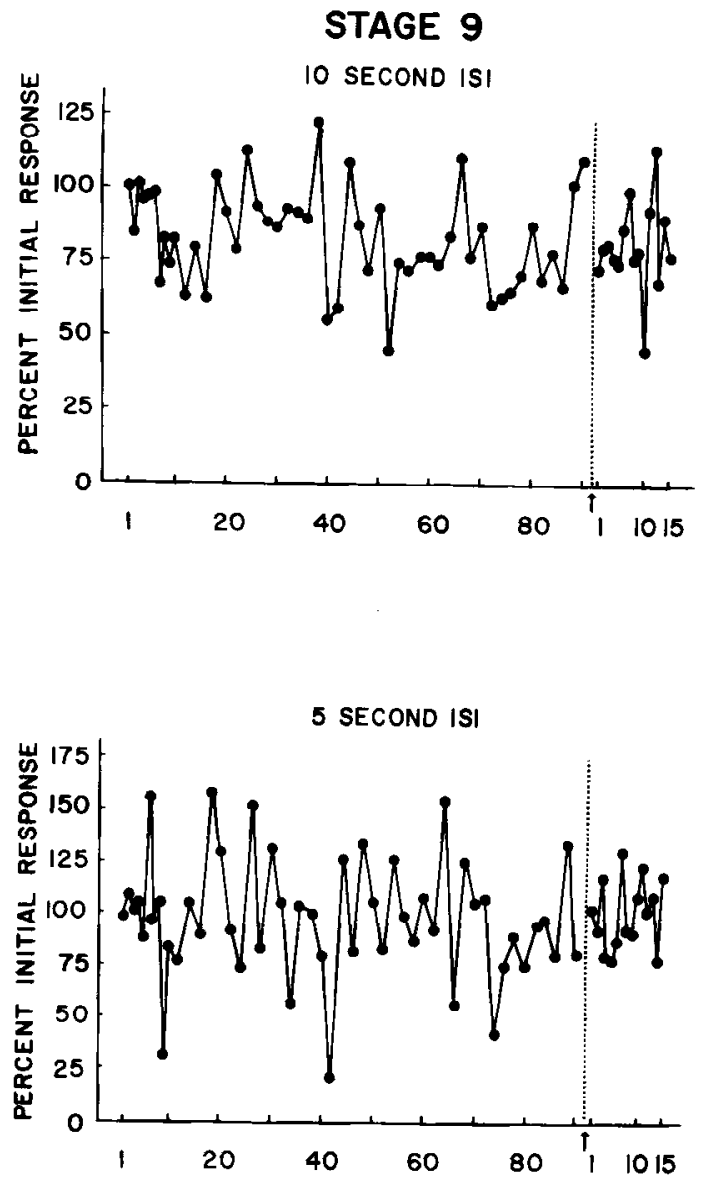

I SECOND |S|

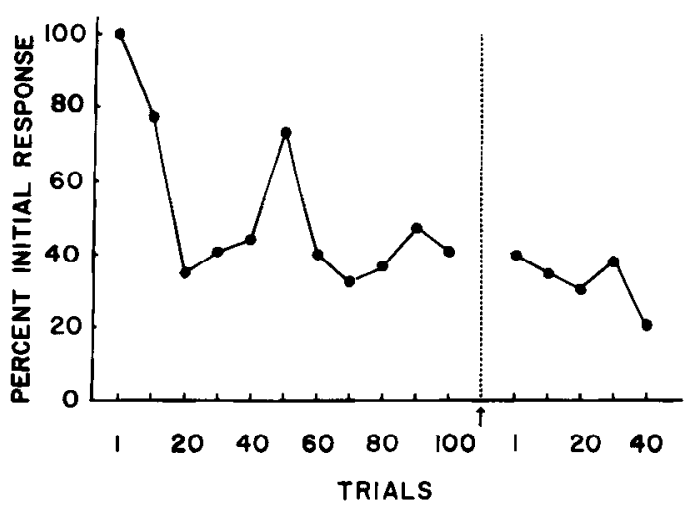

Figure 5. Habituation and dishabituation in stage 9 animals. ISIs of 10,5 , and $1 \sec (n=5$ for each) were used. The dashed line and arrow represent tail shock. There was significant habituation only to the $1 \mathrm{sec}$ ISI. No dishabituation was exhibited at any ISI.

stimuli at a 1 sec ISI. An across-trials ANOVA revealed that this prior training produced subsequent habituation to the $1 \mathrm{sec}$ stimuli that was significantly greater than that exhibited in response to the identical $1 \mathrm{sec}$ ISI in the absence of preceding training. $(\mathrm{F}(1,8)=11.35, p<0.02 ; \mathrm{Fig} .6)$. Thus, although no significant habituation was evident at a $10 \mathrm{sec}$ ISI in stage 9 animals, significant effects of that habituation-dishabituation

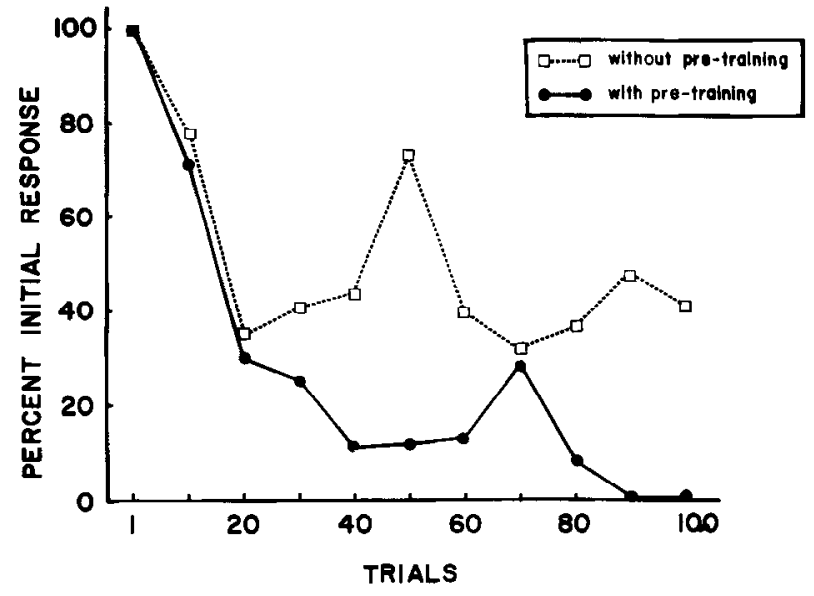

Figure 6. Effect of prior training on habituation. The open boxes and dashed line show habituation for stage 9 animals at $1 \sec$ ISI $(n-5$; these data are the same as shown in Fig. 5, $1 \mathrm{sec}$ ISI). The closed circles and solid line show habituation for stage 9 animals at a $1 \mathrm{sec}$ ISI that was preceded by habituation and dishabituation training at $10 \mathrm{sec}$ ISI. Animals with this prior training showed significantly greater habituation than animals without the prior training.

training can be detected with a subsequent training session at a $1 \mathrm{sec}$ ISI.

\section{Dishabituation}

An interesting difference between stage 9 animals and older animals is that dishabituation appears to be absent at this early developmental stage. Thus, there was no response facilitation following tail shock at any ISI, including the $1 \mathrm{sec}$ ISI that produced significant habituation (Fig. 5).

One possible explanation for the lack of dishabituation is that the animals are simply unresponsive to tail shock, and thus this stimulus would be ineffective as a dishabituating stimulus at this developmental stage. However, this does not appear to be the case, since all animals $(n=15)$ showed a brisk and intense siphon withdrawal in response to tail shock. Moreover, in approximately half of the animals $(n=8)$ it was possible to accurately measure the duration of siphon withdrawal in response to tail shock and compare it with the duration of siphon withdrawal in response to the first tactile (water jet) stimulus of the habituation run. The response to tail shock in these cases was significantly longer than the initial response $\left(t_{7}=4.06, p<0.01\right.$; Fig. 7). The other animals in the group also showed enhanced responsiveness to tail shock, but the duration of their responses could not be measured accurately either because of the release of ink in response to shock (in itself a clear indication that tail shock had a significant impact on the animal) or because of recurrent spontaneous contractions. Taken collectively, these results show that lack of behavioral efficacy of tail shock cannot account for the lack of dishabituation since tail shock is a potent stimulus in eliciting the reflex at this developmental stage.

\section{Interstage comparisons}

Our results have revealed a clear trend in the development of habituation and dishabituation in progressively older juvenile Aplysia. This trend can be further demonstrated by comparing the magnitude of habituation produced by each ISI at different developmental stages. Four different ISIs have been used (30, 10,5 , and $1 \mathrm{sec}$ ), and, in each case, significantly greater habit- 


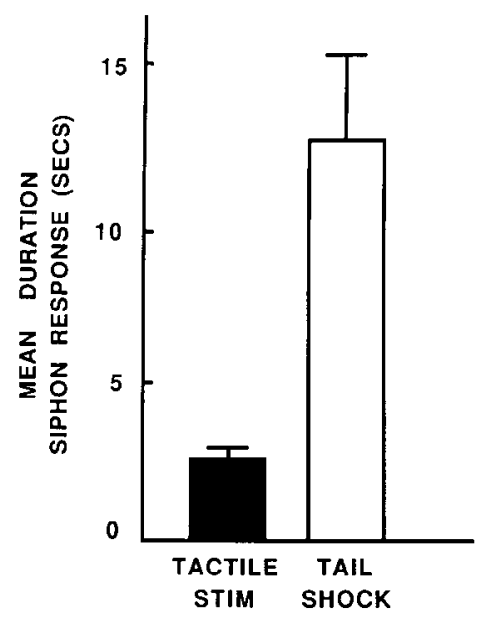

Figure 7. Response of stage 9 animals to tail shock. Mean duration of siphon withdrawal in response to the first tactile stimulus (water jet) to the siphon (black bar) and mean duration of siphon withdrawal in response to tail shock (white bar). The response to tail shock was significantly longer than the response to the tactile stimulus.

uation was produced in older stages than in younger stages: 30 sec ISI $(\mathrm{F}(2,11)=3.5, p<0.05), 10 \mathrm{sec}$ ISI $(\mathrm{F}(2,12)=3.8$, $p<0.05)$, $5 \sec$ ISI $(\mathrm{F}(2,12)=18.5, p<0.001)$, and 1 sec ISI $(\mathrm{F}(2,12)=9.07, p<0.01)$. These data are shown in Figure 8, which expresses the magnitude of habituation (as an average percentage habituation score) exhibited in response to each of the 4 ISIs used, across juvenile developmental stages. For each ISI there is a clear and significant trend for greater habituation at later developmental stages.

The effects of a $1 \mathrm{sec}$ ISI in animals at stages 9-11 of juvenile development are shown in Figure 9, which summarizes our basic findings. Significant habituation was present at each developmental stage tested. Moreover, the animals showed progressively greater habituation (in response to the same $1 \mathrm{sec}$ ISI) as they developed. Following the ANOVA described above $(\mathrm{F}(2,12)=9.07, p<0.01)$, individual planned comparisons showed significantly greater habituation in stages 10 and 11 than in stage 9 ( $p<0.01$ in each case). In contrast to habituation, dishabituation was absent in stage 9 animals, appearing only in

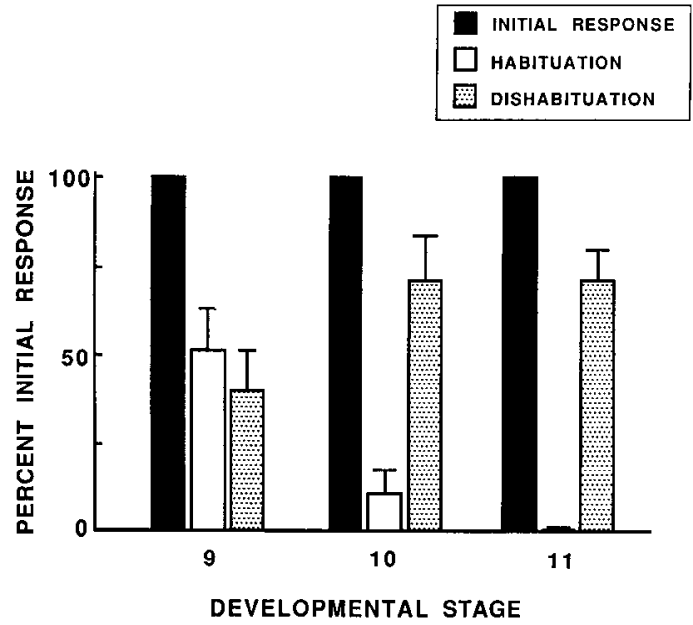

Figure 9. Summary of habituation and dishabituation for stages 911. Summarized data are for a $1 \mathrm{sec}$ ISI. The black bar shows the initial response $(100 \%)$; the white bar shows habituation (the mean of the last trial for the habituation series); the stippled bar shows dishabituation (the mean of the first trial following tail shock). Older animals showed greater habituation than younger animals. There was no dishabituation in stage 9 , whereas there was significant dishabituation in stages 10 and 11.

the next developmental stage (stage 10 ), approximately $5 \mathrm{~d}$ later. Thus, different forms of nonassociative learning emerge at different stages of juvenile development in Aplysia.

\section{Discussion}

\section{Development of learning in Aplysia}

\section{Habituation}

In our studies investigating the development of learning in juvenile Aplysia we have found that both the siphon withdrawal and gill withdrawal components of the defensive withdrawal reflex are functional as soon as the organs emerge in juvenile stages 9 and 10, respectively (Rankin et al., 1987). Habituation is present in each response component as early as we have examined (stage 9 for siphon withdrawal, stage 11 for gill withdrawal). In this paper we have focused our attention on the

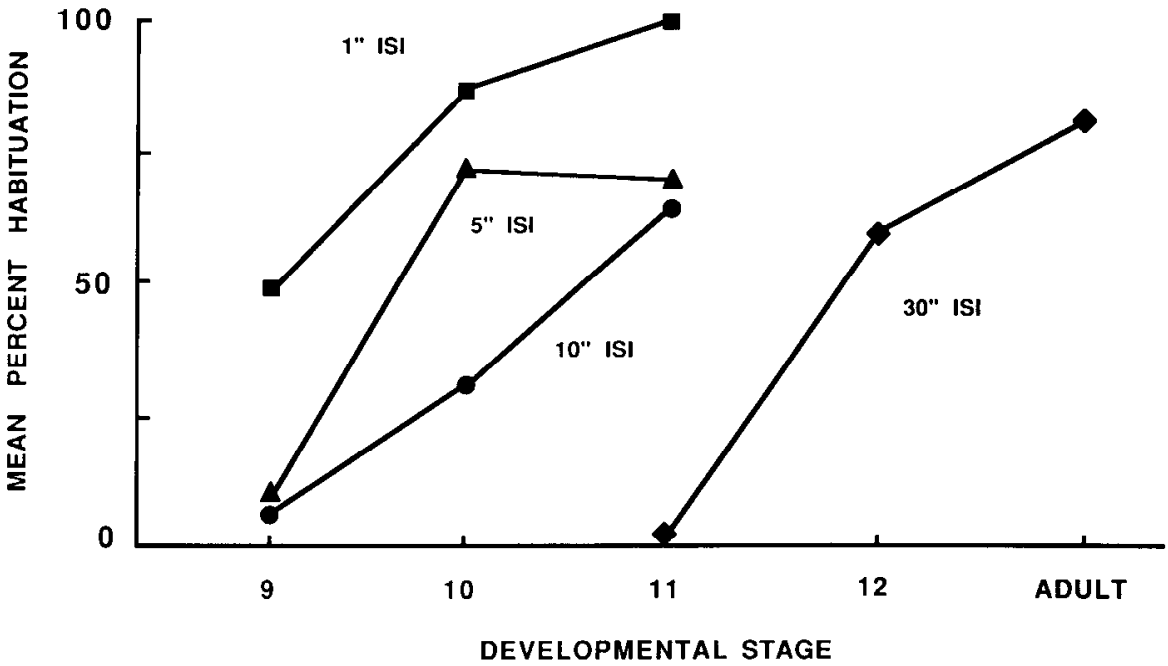

DEVELOPMENTAL STAGE
Figure 8. Development of the ISI function for habituation. The mean percentage of habituation (i.e., percentage change from the initial response-see Materials and Methods) to 4 different ISIs $(1,5,10$, and $30 \mathrm{sec})$ is shown as a function of developmental stage. There was a significant increase in habituation as a function of age for all 4 ISIs. 
siphon withdrawal component of the reflex. Qualitatively similar results have been obtained for the gill withdrawal component, which will be discussed in the third paper of this series (Nolen et al., 1987).

Although habituation of siphon withdrawal is present as early in development as stage 9, it exists in a relatively immature form. Significant within-session habituation is produced only with a very short ( $1 \mathrm{sec}$ ) ISI. As the animals continue to develop in stages 10 and 11 , significantly greater habituation is produced in response to all 3 ISIs tested (1, 5, and $10 \mathrm{sec})$. Moreover, even in later juvenile stages, further development of habituation is evident. In response to a $30 \mathrm{sec}$ ISI, stage 11 animals do not show significant habituation, whereas stage 12 animals do. However stage 12 animals show significantly less habituation to this same $30 \mathrm{sec}$ ISI than do adult animals. Thus, in examining habituation to comparable ISIs across developmental stages, there is clear and progressive development in the magnitude of habituation exhibited in response to a variety of ISIs (ranging from 1 to $30 \mathrm{sec}$ ) throughout most of the juvenile life of Aplysia.

Further evidence for the progressive development of habituation can be gained by examining the acquisition profiles for different ISIs within particular developmental stages. For example, in stage 9 significant habituation occurs to a $1 \mathrm{sec}$ ISI but not to 5 or $10 \mathrm{sec}$ ISIs; in stage 10 to 1 and $5 \mathrm{sec}$ ISIs but not to a $10 \mathrm{sec}$ ISI; and in stage 11 to all 3 ISIs. Moreover, a comparison of the magnitude of habituation as a function of ISI revealed a significant and systematic trend, with animals in each stage showing greater habituation to longer intervals. However, for these within-stage comparisons, the differences in habituation at different ISIs cannot necessarily be attributed solely to differences in ISI training, since training and testing conditions are confounded. The appropriate analysis for such a comparison would require training animals with different ISIs and then testing all the animals with the same ISI (see, for example Davis and Wagner, 1968; Davis, 1970). However, in conjunction with the results described above, where identical ISIs are examined across developmental stages, our data show that habituation is present as soon as the siphon response system emerges during ontogeny and that habituation progressively matures in terms of its ISI function throughout juvenile development.

Finally, it is likely that other features of habituation continue to develop in parallel with the development of the ISI function that we have described. For exmaple, Peretz and Lukowiak (1975) and Lukowiak (1979) examined the development of the CNS control of gill withdrawal in young Aplysia (1.5-20 gm, which would place these animals in late stage 12 ; thus, they are considerably older than the juvenile animals examined in this study). These authors found that the rate of habituation of the gill-withdrawal reflex in young Aplysia is slower than in mature animals and that the young CNS failed to regulate the rate of habituation in response to varying stimulus strength, indicating that habituation may not achieve its entirely mature form even in very late juvenile animals.

\section{Dishabituation}

Whereas habituation was present at the earliest developmental stage we examined, dishabituation was not. Specifically, dishabituation was not apparent in stage 9; it only emerged 4-7 d later in stage 10. Unlike habituation, dishabituation did not appear to mature progressively across developmental stages. However, we have not yet carried out experiments that would be sensitive to the maturation of dishabituation. For example, there may well be differences in the magnitude or time course of dishabituation at different developmental stages that might be revealed only, for example, by systematically varying the intensity or duration of the dishabituating stimulus.

Interestingly, in stage 10 animals tail shock produced clear and significant dishabituation (in the 5 and $1 \mathrm{sec}$ ISI experiments) but did not facilitate nonhabituated responses (in the 10 sec ISI experiment). This raises the question of the distinction between dishabituation and sensitization. Sensitization refers to a general facilitatory process produced by strong or noxious stimuli that enhances subsequent behavioral responses. Dishabituation has commonly been considered to reflect a special instance of sensitization, in which the facilitatory process is simply superimposed on a decremented or habituated response level (Thompson and Spencer, 1966; Groves and Thompson, 1970; Carew et al., 1971). Thus, the terms dishabituation and sensitization are frequently used interchangeably to describe facilitation of habituated responses, while only the term sensitization is used to describe facilitation of nondecremented responses. Although dishabituation and sensitization are often thought to reflect a common underlying process, in certain instances they may reflect different processes. For example, Whitlow (1975), in his studies of habituation of auditory evoked vasoconstriction responses in rabbits, has shown that a strong stimulus produced facilitation of habituated responses but not of nonhabituated responses (see also Whitlow and Wagner, 1984).

In adult Aplysia the distinction between dishabituation and sensitization can be difficult to assess in behavioral studies, especially in most experimental contexts, in which a strong stimulus would evoke both processes simultaneously (Carew et al., 1971). However, recent results suggest that dishabituation and sensitization can be behaviorally distinguished ontogenetically. Specifically, we have found that whereas dishabituation emerges in stage 10 of juvenile development, sensitization (facilitation of nondecremented responses) does not emerge until several weeks later, during stage 12 (Rankin and Carew, 1986). Interestingly, sensitization in another response system, escape locomotion, also emerges in late stage 12 (Stopfer and Carew, 1986). The developmental separation of dishabituation and sensitization in the siphon withdrawal reflex raises the possibility that dishabituation and sensitization may actually involve different mechanisms. This possibility was first suggested by Hochner and colleagues (1986) and is supported by recent cellular observations of Gingrich and Byrne (1985) and Hochner and coworkers (1985), which suggest that heterosynaptic facilitation in the sensory neurons of $A$ plysia that mediate the gill and siphon withdrawal reflex may be accomplished by 2 mechanisms: (1) spike broadening, which predominates when transmitter release is not depressed (analogous to behavioral sensitization); and (2) transmitter mobilization, which predominates when transmitter release is very depressed (analogous to behavioral dishabituation).

Our behavioral observations concerning the ontogeny of habituation and dishabituation in Aplysia are consistent with previous results of cellular studies by Rayport and Camardo (1984). They examined the identified mucous motor neuron R2 in the isolated CNS of juvenile Aplysia and found that homosynaptic depression is present in stage 9 , while heterosynaptic facilitation emerges in stage 10 and reaches maturity in stages 11 and 12 . These observations in the mucous motor system led Rayport and Camardo to suggest that habituation of the gill and siphon withdrawal reflex (which is mediated by homosynaptic depres- 
TEMPORAL EMERGENCE OF LEARNING

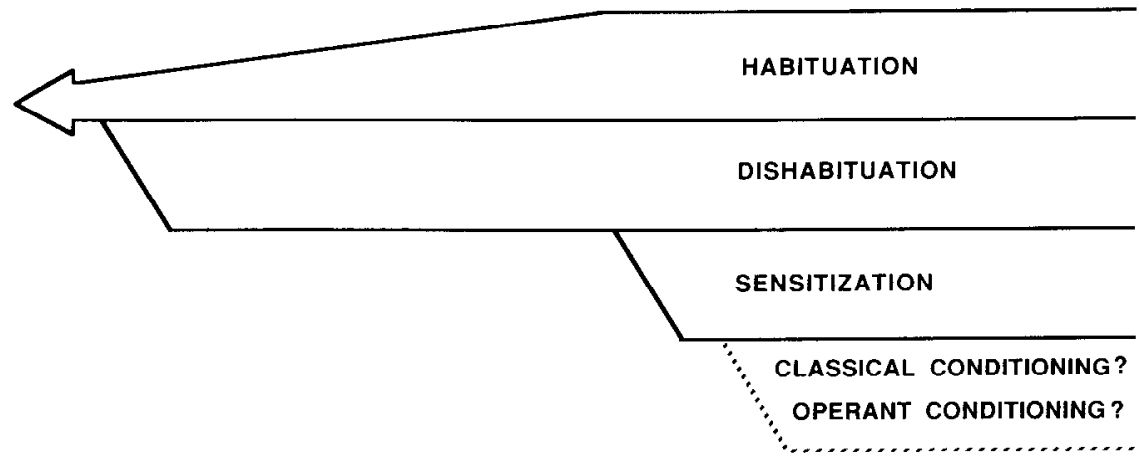

$9>10>11>12 \quad>13$

DEVELOPMENTAL STAGES
Figure 10. Schematic diagram summarizing the temporal emergence of learning in Aplysia. Dashed lines indicate speculation that associative learning (classical and operant conditioning) may emerge at a later developmental stage than nonassociative learning (habituation, dishabituation, and sensitization-see text). sion in the adult) might emerge earlier in development than sensitization (which is mediated by heterosynaptic facilitation), a prediction consistent with our observation that habituation of siphon withdrawal emerges before dishabituation during development.

Our results are summarized and placed in a developmental perspective in the diagram in Figure 10. Habituation is present as early as we have looked, in stage 9, and continues to develop, in terms of its ISI function, throughout the juvenile life of the animal. Dishabituation emerges approximately $4 \mathrm{~d}$ later in stage 10 and, at least within the resolution limits of our present experiments, does not appear to develop further. Finally, sensitization emerges several weeks after dishabituation, during stagc 12 (Rankin and Carew, 1986). Thus, it appears that the simplest form of nonassociative learning, habituation, developmentally precedes somewhat more complex forms, dishabituation and sensitization.

In addition to these simple forms of nonassociative learning, the gill and siphon withdrawal reflexes also exhibit a variety of forms of more complex associative learning, including Pavlovian conditioning, such as differential classical conditioning $(\mathrm{Ca}-$ rew et al., 1983) and context conditioning (Colwill, 1985), as well as operant conditioning (Hawkins et al., 1986). We have no evidence as yet to indicate when these different forms of associative learning emerge during development, but an intriguing possibility (and one that we hypothesize in Fig. 10) is that they may emerge at developmentally later stages than nonassociative learning, implying that there may be an ontogenetic progression in the development of learning from simple to more complex forms.

There is precedent for this suggestion in mammalian studies. For example, Rudy and colleagues (e.g., Rudy and Hyson, 1982, 1984; Hyson and Rudy, 1984) examined the ontogeny of both reflexive and learned reactions to acoustic stimuli in neonatal rats and found that reflex reactions to tonal stimulation emerged earlier in ontogenesis than the capacity to learn about those stimuli. Moreover, they found that rat pups could habituate to acoustic stimuli before they showed Pavlovian conditioning to the same stimuli and that simple forms of conditioning onto- genetically preceded more complex forms (such as differential conditioning). Similar examples exist in the analysis of the ontogeny of nonassociative learning in mammals. For example, Stehouwer and Campbell (1978) investigated habituation of a forelimb withdrawal response in neonatal rats and found that sensitization appeared to emerge at a later time ontogenetically than habituation. Thus, in altricial mammalian species, as well as in Aplysia, there is evidence to support the notion that the emergence of simple forms of learning developmentally precedes the emergence of more complex forms.

Aspects of this developmental sequence may reflect the progressive maturation of the relevant sensory systems necessary for learning. For cxamplc, Vogt and Rudy (1984), in their study of the development of reflexive and learned responses to gustatory stimulation in neonatal rats, found that the capacity to both detect and reflexively respond to sucrose emerged before the capacity for learned control of taste-guided behaviors. In addition, Campbell and Ampuero (1985) found that, in classical conditioning of heart rate in preweanling and weanling rats, the emergence of conditioned responses to tone and light stimuli parallels the sequential order of maturation of the 2 sensory modalities (audition preceding vision). In Aplysia the gill and siphon withdrawal reflexes appear to assume the mature form very early in juvenile development (Rankin et al., 1986). Therefore, the subsequent systematic emergence of different forms of both nonassociative and associative learning in Aplysia may reflect the maturation of the neuronal mechanisms critically responsible for the learning per se. A cellular analysis of the ontogeny of learning in this simple reflex system of $A$ plysia may enable us to distinguish between nonspecific maturational effects (e.g., in the development of sensory and motor systems) and specific cellular changes that directly contribute to the learning process itself.

\section{Development of memory in Aplysia}

Thus far, we have focused our attention on the development of learning in Aplysia; however, our data may provide some initial insights into the development of memory as well. For example, the ISI function for habituation can provide a rudimentary tool 
with which to assess short-term memory: In order for an animal to habituate to a particular stimulus, its nervous system must somehow register and store the information that a prior stimulus has occurred. Thus, the interval between stimuli that permits habituation to take place can provide a measure of the temporal holding capacity (memory) of that system. This type of memory would fall into the general category of short-term memory, e.g., involving some activity function such as arousal followed by decay, commonly used to distinguish it from long-term memory, e.g., involving some structural alteration (see, for example, Anderson and Bower, 1973; Wagner, 1976). Using the ISI function as an index, it appears that short-term memory in Aplysia progressively develops throughout the entire juvenile period into the adult stage. The type of very short-term memory reflected by the ISI function is likely to represent what has been called "refractory-like" memory in mammalian systems (e.g., see Davis, 1970). For discursive purposes we will refer to this form of short-term memory in Aplysia as "immediate" memory.

There is a suggestion in our data that a second type of shortterm memory with a somewhat longer time course than immediate memory may also be present early in juvenile development. For example, we found that no habituation occurred to a $10 \mathrm{sec}$ ISI in stage 9 animals. Nonetheless, we found that preexposure to this $10 \mathrm{sec}$ ISI followed by dishabituation significantly increased subsequent habituation to a shorter $(1 \mathrm{sec})$ ISI, even if that preexposure occurred $15 \mathrm{~min}$ before the $1 \mathrm{sec}$ ISI training. Thus, the prior training produced an effect that had a time course of several minutes, reflecting a somewhat extended form of short-term memory, on the order of minutes rather than seconds. These results illustrate an important point first emphasized by Davis and Wagner (1968), namely, that training and testing can easily be confounded in the analysis of habituation. Specifically, there was no immediate (within-session) memory evident at a $10 \mathrm{sec}$ ISI, since no habituation occurred at this interval. Nonetheless, significant effects of that training could still be detected in a subsequent $1 \mathrm{sec}$ ISI test session. These data are also interesting from a functional point of view, since they show that stimuli delivered at a rate that has no overt behavioral effect at the time of training can nonetheless have a significant effect on subsequent learning.

Our data suggest that during ontogeny the capacity for shortterm memory develops progressively in Aplysia. In mammals it has previously been shown that short-term memory of habituation can develop systematically during ontogeny. For example, File and Scott (1976) showed that preweanling rats exhibited a progressive development of retention of short-term (30-60 $\mathrm{min}$ ) habituation to air puffs as the animals matured in the first 2 weeks postpartum, whereas no long-term retention $(24 \mathrm{hr})$ was observed. It will be of interest to determine whether short-term memory in Aplysia, as measured both in the pretraining paradigm described above and in simple retention studics, devclops systcmatically throughout juvenile ontogeny in a fashion similar to "immediate" memory.

In addition to short-term memory, Aplysia is also capable of long-term memory in this reflex system. For example, long-term habituation and sensitization have been shown to last several weeks (Carew et al., 1972; Pinsker et al., 1973), and classical conditioning has been found to persist for at least a week (Carew et al., 1981). Thus, it will be of interest to examine the ontogenetic timetable for the emergence of these different forms of long-term memory and compare these timetables to those for short-term memory. In this way it may be possible to examine the relationships between short- and long-term processes. It has been suggested on the basis of theoretical grounds (Wagner, 1976) and cellular data (Carew and Kandel, 1973, 1974; Castellucci et al., 1978) that short- and long-term habituation may utilize at least some aspects of a common underlying mechanism. Insights into this question may be obtained by examining whether these 2 forms of memory can be dissociated during development or whether their temporal emergence and maturational time courses are tightly coupled throughout ontogeny.

In conclusion, the ultimate goal of this work is to provide a preparation in which it is possible to study the development of different forms of learning and memory on behavioral, cellular, and ultimately molecular levels. In this paper we have shown that for the siphon withdrawal reflex, different forms of nonassociative learning emerge according to different ontogenetic timetables and that different forms of short-term memory also appear to emerge and develop systematically. In the last paper of this series (Nolen et al., 1986), we describe experiments that focused on the gill withdrawal component of the reflex, as well as on an analysis of the cental neuronal correlates underlying the development of learning in Aplysia.

\section{References}

Amsel, A., and M. Stanton (1980) Ontogeny and phylogeny of paradoxical reward effects. In Advances in the Study of Behavior, Vol. 2, pp. 227-274, Academic, New York.

Anderson, J. R., and G. H. Bower (1973) Human Associative Memory, Winston, Washington, DC.

Campbell, B. A., and M. X. Ampuero (1985) Dissociation of autonomic and behavioral components of conditioned fear during development in the rat. Behav. Neurosci. 99: 1089-1103.

Campbell, B. A., and X. Coulter (1976) The ontogenesis of learning and memory. In Neural Mechanisms of Learning and Memory, M. R. Rosenzweig and E. L. Bennett, eds., pp. 71-74, MIT Press, Cambridge, MA.

Campbell, B. A., and N. E. Spear (1972) Ontogeny of memory. Psychol. Rev. 79: 215-236.

Carew, T. J. (1986) Advances in the cellular analysis of learning in Aplysia. In Cellular Basis of Learning: Dahlem Konferenzen, J.-P. Changeux and M. Konishi, eds., Springer, New York (in press).

Carew, T. J., and E. R. Kandel (1973) Acquisition and retention of long-term habituation: Correlation of behavioral and cellular processes. Science 182: 1158-1160.

Carew, T. J., and E. R. Kandel (1974) A synaptic analysis of the interrelationship between different behavioral modifications in Aplysia. In Synaptic Transmission and Neuronal Interaction, M. V. L. Bennett and E. R. Kandel, eds., pp. 187-215, Raven, New York.

Carew, T. J., and E. R. Kandel (1977) Inking in Aplysia californica. I. The central program for inking. J. Neurophysiol. 40: 708-720.

Carew, T. J., and C. L. Sahley (1986) Invertebrate learning: From behavior to molecules. Annu. Rev. Neurosci. 9: 435-487.

Carew, T. J., V. Castellucci, and E. R. Kandel (1971) Analysis of dishabituation and sensitization of the gill-withdrawal reflex in Aplysia. Int. J. Neurosci. 2: 79-98.

Carcw, T. J., H. M. Pinsker, and E. R. Kandel (1972) Long-term habituation of a defensive withdrawal reflex in Aplysia. Science 175: 451-454.

Carew, I. J., V. Castellucci, J. H. Byrne, and E. R. Kandel (1979) A quantitative analysis of the relative contribution of central and peripheral neurons to the gill-withdrawal reflex in Aplysia. J. Neurophysiol. 42: 497-509.

Carew, T. J., E. T. Walters, and E. R. Kandel (1981) Classical conditioning in a simple withdrawal reflex in Aplysia. J. Neurosci. 1: 1426-1437

Carew, T. J., R. D. Hawkins, and E. R. Kandel (1983) Differential classical conditioning of a defensive withdrawal reflex in Aplysia californica. Science 219: 397-400.

Castellucci, V. F., T. J. Carew, and E. R. Kandel (1978) Cellular analysis of long-term habituation in the gill-withdrawal reflex of $A p l y-$ sia californica. Science 202: 1306-1308. 
Castellucci, V. F., E. R. Kandel, J. H. Schwartz, F. D. Wilson, A. C. Nairn, and P. Greengard (1980) Intracellular injection of the catalytic subunit of cyclic AMP-dependent protein kinase simulates facilitation of transmitter release underlying behavioral sensitization in Aplysia. Proc. Natl. Acad. Sci. USA 77: 7492-7496.

Castellucci, V. F., A. Nairn, P. Greengard, J. H. Schwartz, and E. R. Kandel (1982) Inhibitor of adenosine $3^{\prime}: 5^{\prime}$-monophosphate-dependent protein kinase blocks presynaptic facilitation in Aplysia. J. Neurosci. 2: 1673-1681.

Colwill, R. M. (1985) Context conditioning in Aplysia californica. Soc. Neurosci. Abstr. 11: 796.

Davis, M. (1970) Effects of interstimulus interval length and variability on startle response habituation in the rat. J. Comp. Physiol. Psychol. 72: $177-192$.

Davis, M., and A. R. Wagner (1968) Startle responsiveness after habituation to different intensities of tone. Psychonomic Sci. 12: 337338.

File, S. E., and E. M. Scott (1976) Acquisition and retention of habituation in the preweanling rat. Dev. Psychobiol. 9: 97-107.

Gingrich, K. J., and J. H. Byrne (1985) Stimulation of synaptic depression, posttetanic potentiation, and presynaptic facilitation of synaptic potentials from sensory neurons mediating gill-withdrawal reflex in Aplysia. J. Neurophysiol. 53: 652-669.

Groves, P. M., and R. F. Thompson (1970) IIabituation: A dualprocess theory. Psychol. Rev. 77: 419-458.

Hawkins, R. D., T. W. Abrams, T. J. Carew, and E. R. Kandel (1983) A cellular mechanism of classical conditioning in Aplysia: Activitydependent amplification of presynaptic facilitation. Science 219:400405.

Hawkins, R. D., G. A. Clark, and E. R. Kandel (1986) Cell biological studies of learning in simple vertebrate and invertebrate systems. In Handbook of Physiology, Section I. The Nervous System, Vol. 6: Higher Functions of the Nervous System, F. Plum, ed., American Physiological Society, Bethesda, MD (in press).

Hochner, B., S. Schacher, M. Klein, and E. R. Kandel (1985) Presynaptic facilitation in Aplysia sensory neurons: A process independent of $\mathrm{K}^{+}$current modulation becomes important when transmitter release is depressed. Soc. Neurosci. Abstr. 11:29.

Hochner, B., M. Klein, S. Schacher, and E. R. Kandel (1986) Additional component in the cellular mechanism of presynaptic facilitation contributes to behavioral dishabituation in Aplysia. Proc. Natl. Acad. Sci. USA 83: 8794-8797.

Hyson, R. L., and J. W. Rudy (1984) Ontogenesis of learning: II. Variation in the rat's reflexive and learned responses to acoustic stimulation. Dev. Psychobiol. 17: 263-283.

Jacob, M. H. (1984) Neurogenesis in Aplysia californica resembles nervous system formation in vertebrates. J. Neurosci. 4: 1225-1239.

Kandel, E. R., T. Abrams, L. Bernier, T. J. Carew, R. D. Hawkins, and J. H. Schwart7. (1983) Classical conditioning and sensitization share aspects of the same molecular cascade in Aplysia. Cold Spring Harbor Symp. Quant. Biol. 48: 821-830.

Klein, M., and E. R. Kandel (1978) Presynaptic modulation of voltagedependent $\mathrm{Ca}^{++}$current: Mechanism for behavioral sensitization. Proc. Natl. Acad. Sci. USA 75: 3512-3516.

Klein, M., and E. R. Kandel (1980) Mechanisms of calcium current modulation underlying presynaptic facilitation and behavioral sensitization in Aplysia. Proc. Natl. Acad. Sci. USA 77: 6912-6916.

Kriegstein, A. K. (1977a) Development of the nervous system of $\mathrm{Aply}$ sia californica. Proc. Natl. Acad. Sci. USA 74: 375-378.

Kriegstein, A. R. (1977b) Stages in the post-hatching development of Aplysia californica. J. Exp. Zool. 199: 275-288.

Kriegstein, A. R., V. Castellucci, and E. R. Kandel (1974) Metamorphosis of Aplysia californica in laboratory culture. Proc. Natl. Acad. Sci. USA 71: 3654-3658.

Lukowiak, K. (1979) The development of central nervous system control of the gill withdrawal reflex evoked by siphon stimulation in Aplysia. Can. J. Physiol. Pharmacol. 57: 987-997.

Lynch, G., J. L. McGaough, and N. M. Weinburger, eds. (1984) Neurobiology of Learning and Mernory, Guilford, New York.

Nolen, T. G., E. Marcus, and T. J. Carew (1987) Development of learning and memory in Aplysia. III. Central neuronal correlates. J. Neurosci. 7: 144-153.
Peretz, B., and K. Lukowiak (1975) Age-dependent CNS control of the habituating gill withdrawal reflex and of correlated activity in identified neurons in Aplysia. J. Comp. Physiol. 103: 1-17.

Pinsker, H., T. J. Carew, W. Hening, and E. R. Kandel (1973) Longterm sensitization of a defensive withdrawal reflex in Aplysia californica. Science 182: 1039-1042.

Pinsker, H., I. Kupfermann, V. Castellucci, and E. R. Kandel (1970) Habituation and dishabituation of the gill-withdrawal reflex in Aplysia. Science 167: 1740-1742.

Quinn, W. G. (1984) Work in invertebrates on the mechanisms underlying learning. In Biology of Learning, P. Marler and H. Terrace, eds., pp. 197-246, Dahlem Konferenzen, Berlin.

Kankin, C. H., and T. J. Carew (1985) Development of learning and memory in Aplysia: II. Habituation, sensitization and short term memory. Soc. Neurosci. Abstr. 11: 643.

Rankin, C. H., and T.J. Carew (1986) Dishabituation and sensitization emerge as separate processes during development in Aplysia. Soc. Neurosci. Abstr. 12: 398

Rankin, C. H., M. Stopfer, E. A. Marcus, and T. J. Carew (1987) Development of learning and memory in Aplysia. I. Functional assembly of the siphon withdrawal reflex. J. Ncurosci. 7: 120-132.

Rayport, S., and J. S. Camardo (1984) Differential emergence of cellular mechanisms mediating habituation and sensitization in the developing Aplysia nervous system. J. Neurosci. 4: 2528-2532.

Rayport, S., and E. R. Kandel (1980) Developmental modulation of an identified electrical synapse: Functional uncoupling. J. Neurophysiol. 44: 555-567.

Rudy, J. W., and R. L. Hyson (1982) Consummatory response conditioning to an auditory stimulus in neonatal rats. Behav. Neural Biol. 34: $209-214$

Rudy, J. W., and R. L. Hyson (1984) Ontogenesis of learning: III. Variation in the rat's differential reflexive and learned responses to sound frequencies. Dev. Psychobiol. 17: 285-300.

Schacher, S., E. R. Kandel, and R. Woolley (1979a) Development of neurons in the abdominal ganglion of Aplysia californica. I. Axosomatic synaptic contacts. Dev. Biol. 71: 163-175.

Schacher, S., E. R. Kandel, and R. Woolley (1979b) Development of neurons in the abdominal ganglion of Aplysia californica. II. Nonneural support cells. Dev. Biol. 71: 176-190.

Seigelbaum, S. A., J. S. Camardo, and E. R. Kandel (1982) Serotonin and cyclic AMP close single $\mathrm{K}^{+}$channels in Aplysia sensory neurons. Nature 299: 413-417.

Squire, L. R., and N. Butters, eds. (1984) Neuropsychology of Memory, Guilford, New York.

Stehouwer, D. J., and B. A. Campbell (1978) Habituation of the forelimb-withdrawal response in neonatal rats. J. Exp. Psychol. 2: 104119.

Stopfer, M., and T. J. Carew (1986) Development of escape locomotion in Aplysia. Soc. Neurosci. Abstr. 12: 399.

Stopfer, M., and T. J. Carew (1986) A quantitative analysis of the relationship between gill amplitude and siphon duration in the defensive withdrawal reflex of Aplysia. Behav. Neurosci. (in press).

Thompson, R. F., and W. A. Spencer (1966) Habituation: A model phenomenon for the study of the neuronal substrates of behavior. Psychol. Rev. 73: 16-43.

Vogt, M. B., and J. W. Rudy (1984) Ontogenesis of learning: I. Variation in the rat's reflexive and learning responses to gustatory stimulation. Dev. Psychobiol. 17: 11-33.

Wagner, A. R. (1976) Priming in STM: An information-processing mechanism for self-generated or retrieval-generated depression of performance. In Habituation: Perspectives From Child Development, Animal Behavior, and Neurophysiology, T. J. Tighe and R. N. Leaton, eds., pp. 95-128, Erlbaum, Hillsdale, NJ.

Whitlow, J. W., Jr. (1975) Short-term memory in habituation and dishabituation. J. Exp. Psychol. 104: 189-206.

Whitlow, J. W., Jr., and A. R. Wagner (1984) Memory and habituation. Reprinted from Habituation, Sensitization, and Behavior, H. V. S. Peeke and L. Petrinovich, eds., pp. 103-153, Academic, New York. Winer, B. (1962) Statistical Principles in Experimental Design. McGraw-Hill, New York. 